\title{
Minimally Invasive Renal Transplantation
}

\author{
Ole Øyen \\ Oslo University Hospital Rikshospitalet \\ Clinic for Specialised Medicine and Surgery, \\ Norway
}

\section{Introduction}

During the last 20 years minimally invasive surgery (MIS) has replaced many open, conventional operations and is now important in almost every facet of abdominal surgery (Harrell \& Beniford, 2005). Benefits regarding postoperative pain, convalescence, return to normal activities, and cosmetic results have been proven for a wide range of MIS procedures.

Within the field of transplantation, laparoscopic fenestration of lymphoceles in kidney recipients was first described in 1991 (McCullough et al.). Furthermore, laparoscopic living donor nephrectomy (L-LDN) has gained widespread acceptance, since the first procedure was performed in Baltimore, USA in 1995 (Ratner et al., 1995).

Reduction of tissue trauma seems particularly appropriate in the immunosuppressed population, with significantly delayed wound healing and a high "background" complication rate. Due to the immunosuppressive theraphy, the incidences of lymphoceles, wound dehiscence and incisional hernia are distinctly higher in kidney-Tx (KTx) recipients. On this background it is rather surprising that MIS techniques for the renal transplant procedure itself, first have been reported during recent years. Possible explanations for these seemingly conservative attitudes, may include the urge for safe handling of the kidney through sufficient access, for total control during revascularization; and the present unfeasibility of automating the vascular anastomoses.

In 2002, however, a french case report on robotic-assisted (da Vinci system) kidney transplantation, from a deceased donor, was presented (Hoznek et al., 2002). Thereafter, no further cases/series of robotic-assisted KTx seem to have been published.

In 2006 a minimally invasive KTx (MIKT) technique was described in Transplantation and Transplantation Proceedings (Øyen et al., 2006); using a minimal skin incision $(7-9 \mathrm{~cm}$ ) and still giving optimal access to the anastomotic area of the iliac vessels - mostly without using scopic aid. Twentyone consecutive MIKT procedures, performed by a single surgeon was compared to a control group subjected to conventional KTx. Since then, a South Korean group has published two reports (Seong-Pyo et al., 2007; Park et al., 2008) on a videoassisted MIKT technique.

Another MIKT report was contributed by a spanish group (Rosales et al., 2010); a case report describing a laparoscopic KTx technique, without robotic assistance.

Furthermore, in 2010 a minimally invasive technique for renal auto-transplantation was reported (Øyen et al., 2010); by combining 'hand- assisted laparoscopic nephrectomy" and 
'MIKT, using the same incision (7-8 cm) for hand-assistance, kidney harvesting, and transplantation.

The MIKT procedure have so far not gained widespread acceptance and still seem to be at a "pioneer stage". However, considering the rapid evolution of MIS during the last two decades, there is little reason to believe that KTx and Auto-KTx in future will be excluded from this development.

\section{The minimally invasive surgical revolution}

During the last 20 years minimally invasive techniques have revolutionised surgery in general, and in particular have laparoscopic procedures replaced most conventional operations, including advanced surgery on liver, pancreas and intestines. Benefits regarding postoperative pain, convalescence, return to normal activities, and cosmetic results have been proven for a wide range of MIS procedures. The development has been facilitated by improvements in optical and hemostatic equipment (High definition imaging, Ultracision, LigaSure), miniaturization, and the introduction of robotic technology (da Vinci robot system).

The revolutionary MIS development was started by a French gynecologist, with experience from simple laparoscopic procedures like sterilisation, and he actually invented laparascopic cholecystectomy (Dubois et al., 1991). This invention, started in 1987 , has indeed turned out to be the greatest revolution in surgical technique during the last 2000 years. In fact, our conventional instruments for open, conventional surgery (scalpel, scissors, forceps etc) have no further subtleties than those found in archeological findings from Pompei (to be seen in the Archeological Museum of Napoli). The great achievements in surgery during the last part of the $19^{\text {th }}$ century and first part of the $20^{\text {th }}$ century was actually due to developments in anesthesia and bacteriology/septicemiae not in surgical technique.

During the last two decades of rapid MIS evolution, an almost linear correlation between incisional/tissue trauma and postoperative morbidity has been demonstrated.

Within the field of transplantation, laparoscopic fenestration of post-KTx lymphoceles was first described in 1991 (McCullough et. al.). This MIS technique has in recent years taken over as the standard treatment option for lymphoceles, replacing the traditional deroofing by laparotomy. Furthermore, laparoscopic living donor nephrectomy (L-LDN) has gained widespread acceptance, since the first procedure was performed in Baltimore, USA in 1995 (Ratner et al.). Many centres have adopted hand-assisted L-LDN techniques, because this is perceived to be faster, easier and safer than with the strictly laparoscopic technique (Wolf JSJ et al., 1998). By any method, a 6-9 cm incision is required for decent kidney extraction. With hand-assistance/handport the incision must usually be extended to $8-12 \mathrm{~cm}$.

\section{Robotic surgery: The da Vinci robot in renal transplantation; a case report from France (2002)}

\subsection{Method: The da Vinci surgical system}

The da Vinci surgical system (Intuitive Surgical, Inc., Mountain View, California), based on robotic technology and introduced during the first years of this millennium, enabled surgeons to perform delicate and complex MIS operations, without extensive laparoscopic experience - affording excellent vision, precision, dexterity and control. The key components 
of the da Vinci surgical system included: an ergonomically designed console where the surgeon was seated while operating, , four interactive robotic arms, a high-definition 3D vision system, and proprietary so called EndoWrist ${ }^{\circledR}$ instruments. The.da Vinci system was powered by state-of-the-art robotic technology that allowed the surgeon's hand movements to be scaled, filtered and translated into precise movements of the EndoWrist instruments working inside the patient's body.

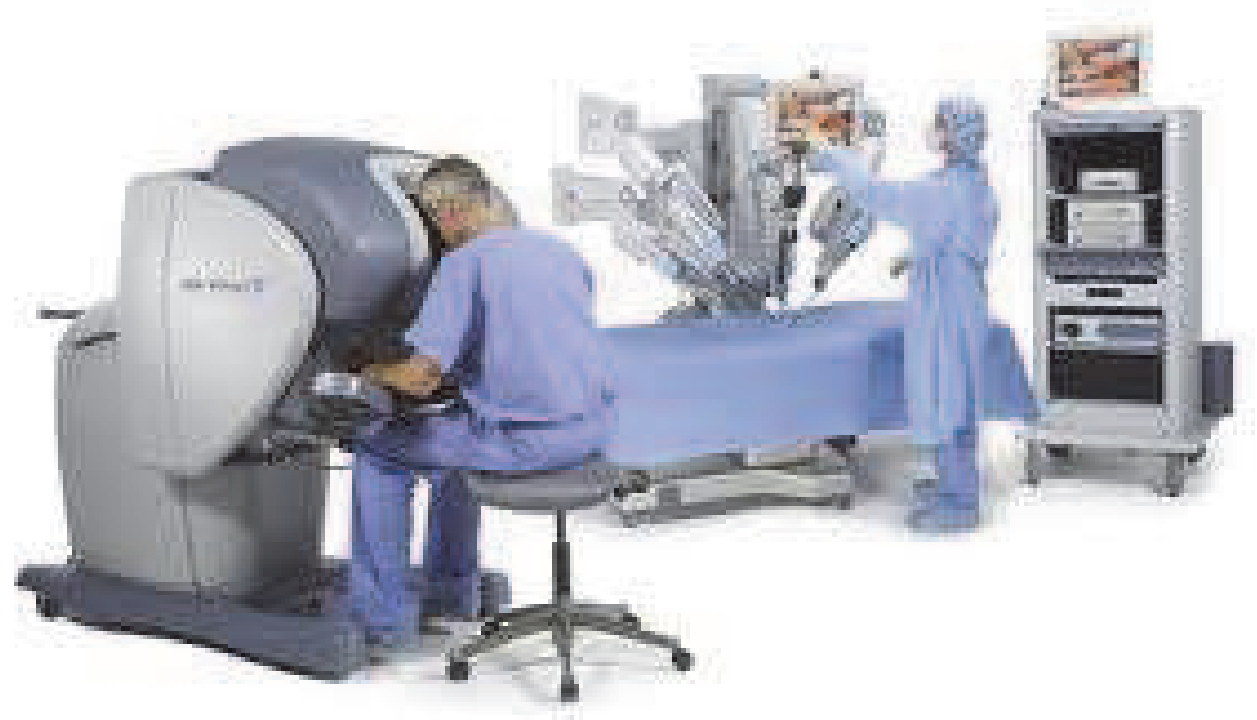

Fig. 1 The da Vinci robotic system.

During the last decade, the da Vinci system has particularly made progress within the field of laparoscopic urology, including radical prostatectomy, simple nephrectomy (not living donor nephrectomy) and pelvic lymph node dissection.

A great prospective feature of robotic surgery is the ability to dissociate the surgeon from the operative field. Specialised operations may be executed at remote hospitals, by a centralized surgeon.

\subsection{Case report on 'da Vinci' KTx}

The paper from 2002 ( Hoznec et. al.) described a right cadaveric kidney transplanted into a 26-year-old male recipient, who had been on hemodialysis for 11 years. Surgery was done with the help of the da Vinci robot, by a "locally remote" surgeon, who completely performed vascular dissection and anastomoses, as well as ureterovesical anastomosis. The role of the assistant by the side of the patient was limited to access creation, exposure, hemostasis and maintaining traction on the running sutures performed by the robot. Operative time was 178 minutes. Robotic assistance made the vascular anastomoses feasible by stereoscopic magnification and ultraprecise visuality and manuvering. Renal perfusion was reported to be excellent with immediate diuresis. Nevertheless, postoperative acute tubular necrosis was first resolved one week post-Tx. 


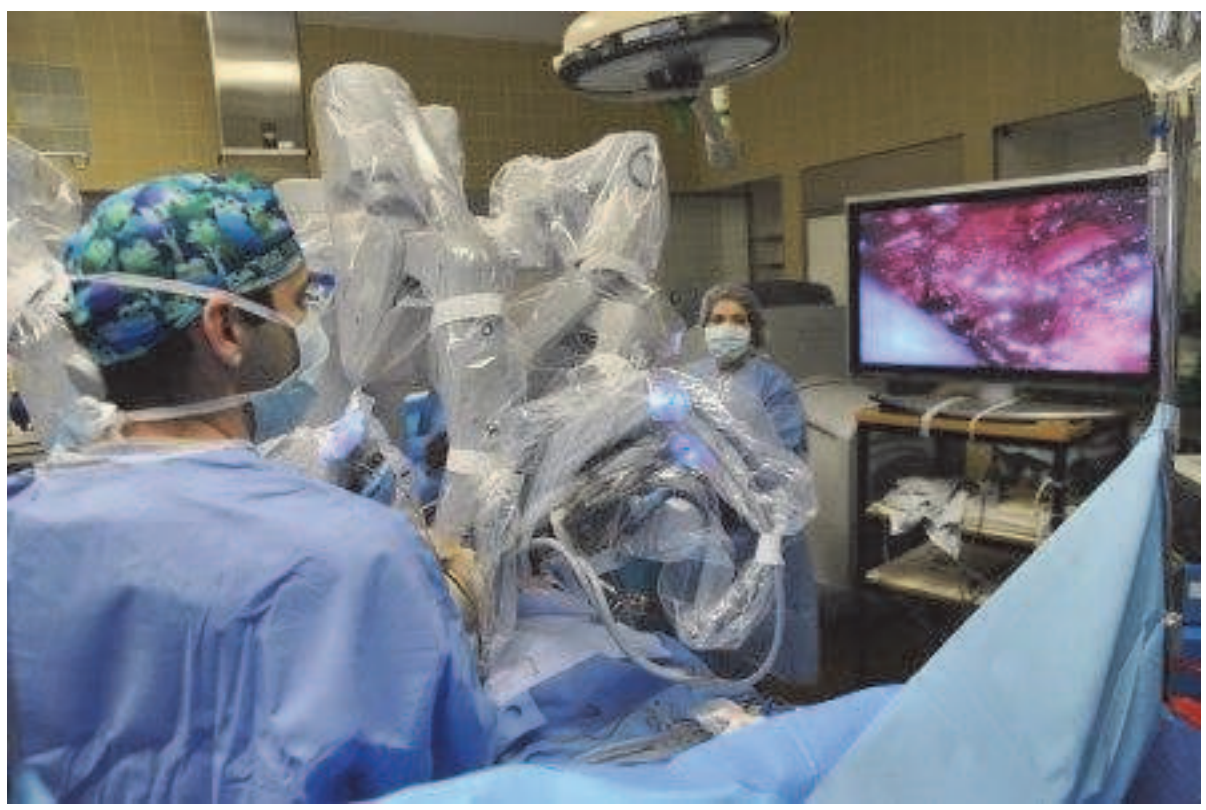

Patient-side cart (Slave)
Sturgegnts console (Nlaster)

\section{Monitor}

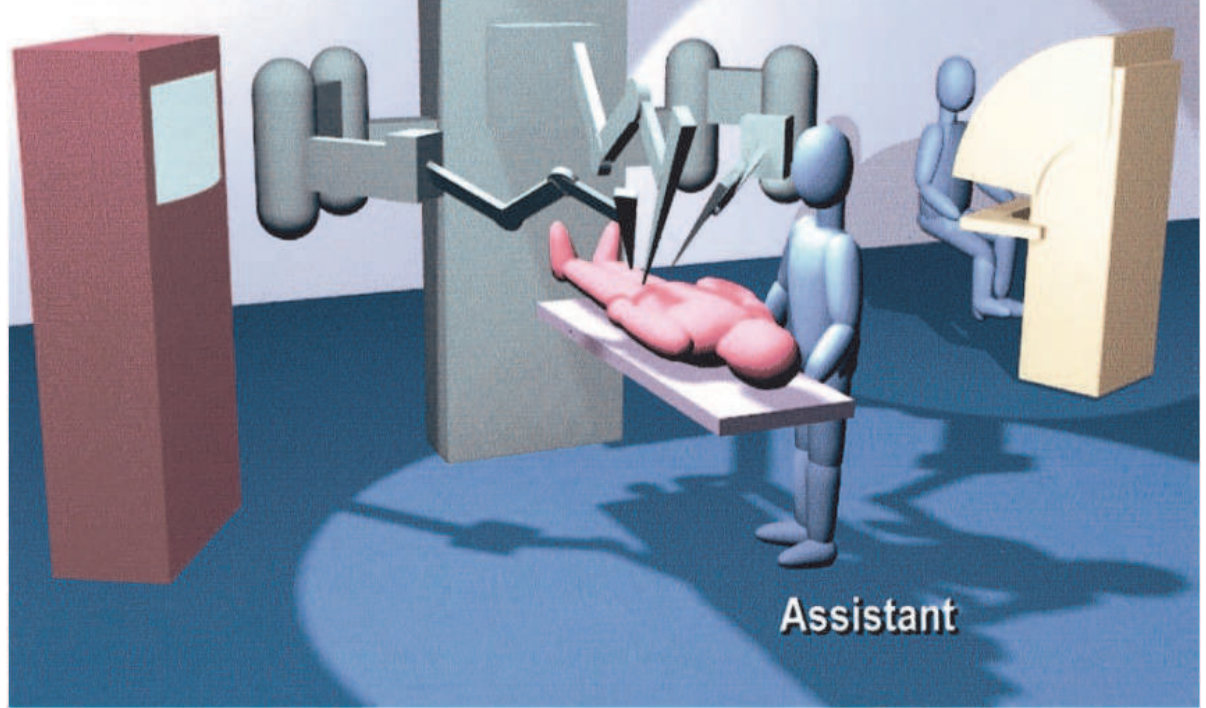

Fig. 2. The da Vinci robot system: Positioning of patient and surgeon. (Hoznek et al., 2002). 
According to the authors, the case demonstrated that robotic assisted kidney transplantation was feasible. However, at that time, technical and cost hindrances was suspected to retard routine use of robots in future.

\subsection{Further course/evolution of the 'da Vinci surgical system' in KTx}

During recent years, the main application of the 'da Vinci robotic system' has been radical prostatectomy. In most other fields of laparoscopy, refined suturing has not been necessary, because ot the evolutionary development in stapling/clipsing devices, Ultracision and LigaSure. This is the main reason why the 'da Vinci system' has not taken over in other laparoscopic fields.

By close literature searches, the French group (nor any other group) does not seem to have reported any further 'da Vinci KTx' cases during the last decade. For the sake of completeness; the 'da Vinci KTx' case was mentioned in a review article about 'Robotic renal surgery' by the same authors (Hoznek et. al., 2004).

In the 'da Vinci KTx' paper, the size of the incision used for kidney introduction, is not indicated. The fact that a $6-9 \mathrm{~cm}$ incision is nevertheless required for decent implantation, and 3 hours 'da Vinci KTx' operating time, may explain why this method for KTx was not found worthy to pursue. In addition to the 6-9 $\mathrm{cm}$ implantation incision, the 'da Vinci' method is dependent on 2-3 laparoscopic ports (10-12 mm each), which are not necessary in the MIKT setting.

In a recent publication (Khanna \& Horgan, 2011) a laboratory training and evaluation technique for robot assisted ex vivo KTx was demonstrated.

\section{Minimally invasive KTx (MIKT); mostly without scopic aid - The Oslo experience (2006)}

In 2005, a MEDLINE search for recent publications (years 2000-2005) containing both 'Kidney transplantation' and 'MIS' yielded 227 hits. However, a careful look at these references revealed that the great majority was about L-LDN, a few presented various MIS procedures in transplanted patients, but none of them were concerned with the transplantation procedure itself. The french da Vinci robot KTx report was not detected by our searches, because 'MIS' /'Laparoscopy' had not been included as key words..

The lack of MIKT publications in the literature was a bit surprising, for several reasons. Firstly, because MIS procedures had been described for all kinds of abdominal surgery, including sophisticated procedures, such as liver and pancreas resections. Secondly, because the potential advantages of reducing incisions/tissue trauma are probably of greater benefit in immunosuppressed patients, with significantly impaired wound healing. Possible explanations might include the urge for safe handling of the kidney through sufficient access, for total control during revascularization; and the present unfeasibility of automating the vascular anastomoses.

\subsection{Developing MIKT: Method/technique}

During the first years of the 21th century a MIKT technique was developed in Oslo, restricting to an appendectomy-like, approximately $8 \mathrm{~cm}$ long incision and with division only of the conjoined tendon (Øyen et al., 2006).

A careful and meticulous "back table" preparation of the kidney prior to transplantation was essential for MIKT, because of limited access to the parenchyma/hilus after 
revascularization. All redundant fatty tissue outside the "hilus-plane" was removed, to get undisturbed access for "complete" hemostatic control. All minor blood vessels, including capsular vessels, were secured by ligation or diathermy. Furthermore, the lymphatic vessels, mostly located alongside the artery, were ligated. The short right renal vein was extended by reconstruction using part of the caval tube caudally.

In the recipient, a 7-9 $\mathrm{cm}$ transverse incision was placed $3-5 \mathrm{~cm}$ above the inguinal ligament, with the medial end $2-3 \mathrm{~cm}$ from the midline. Only the 'conjoined tendon' and hardly any muscular tissue was divided. The iliac vessels were dissected free extraperitoneally, in a minimalistic fashion. A self-retracting system (Omnitract $\left.{ }^{\circledR}\right)$ was introduced, giving medial, vascular exposure while allowing space for the kidney lateral/cranial to the skin incision. The meticulously prepared kidney was then placed in a small/fitting, lateral, retroperitoneal pouch, which has been precooled by ice sludge. All three anastomoses were performed with the kidney in this final "in situ" position. The renal vein was anastomosed to the external iliac vein ('end-to-side'). Therafter, the renal artery was anastomosed to the external iliac artery ('end-to-side'), or in most living donor cases (no aortic cuff) to the internal iliac artery ('end-to-end'). The MIKT access made it necessary to suture the back wall of the vascular anastomoses from the inside. Clamping of the vessels was done in a simplified, one-stage manner, using a Key-Lambert ${ }^{\circledR}$ clamp.

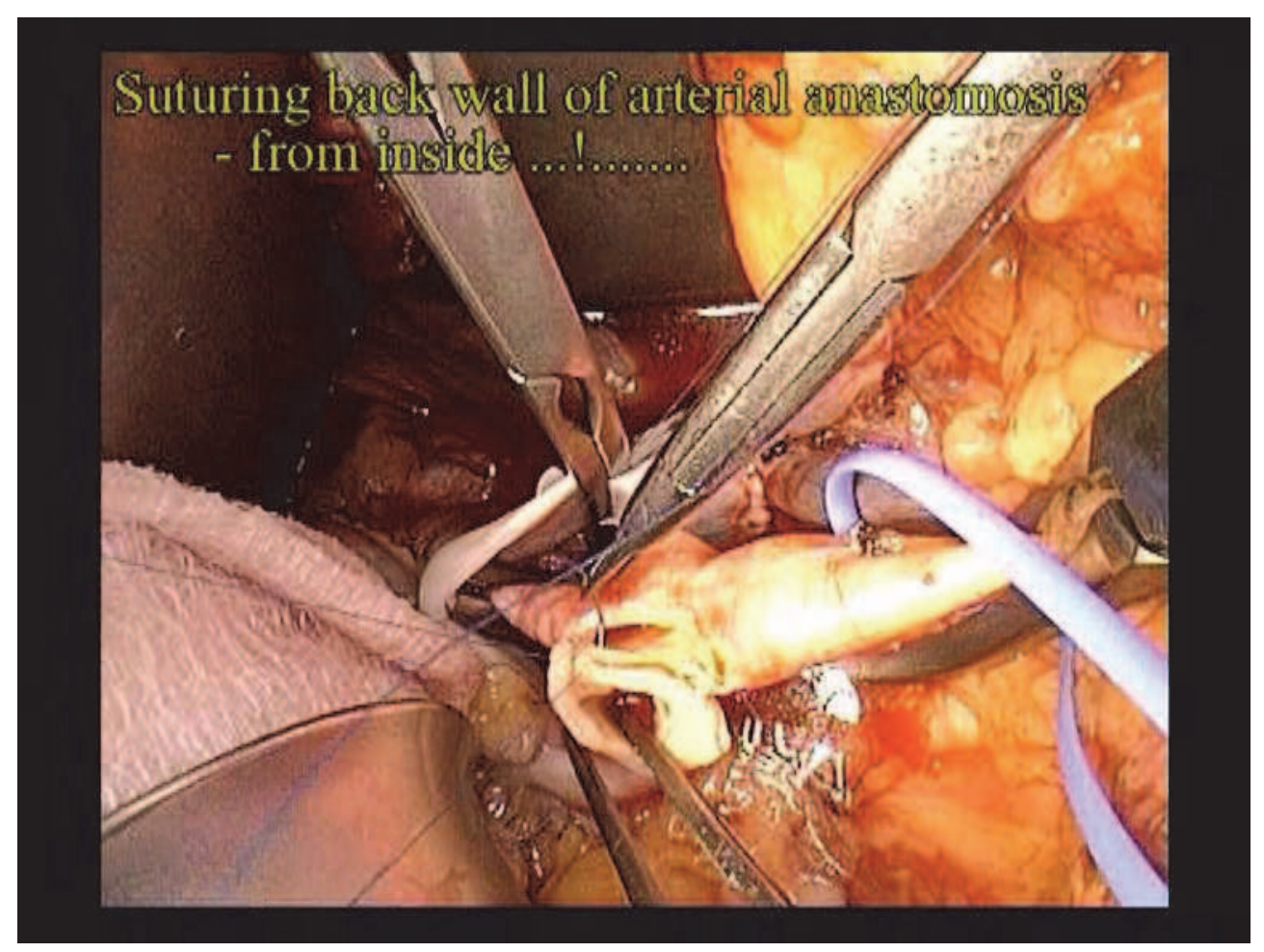

Fig. 3. Suturing the renal artery end-to-side to the external iliac artery (Clamp on renal vein). 


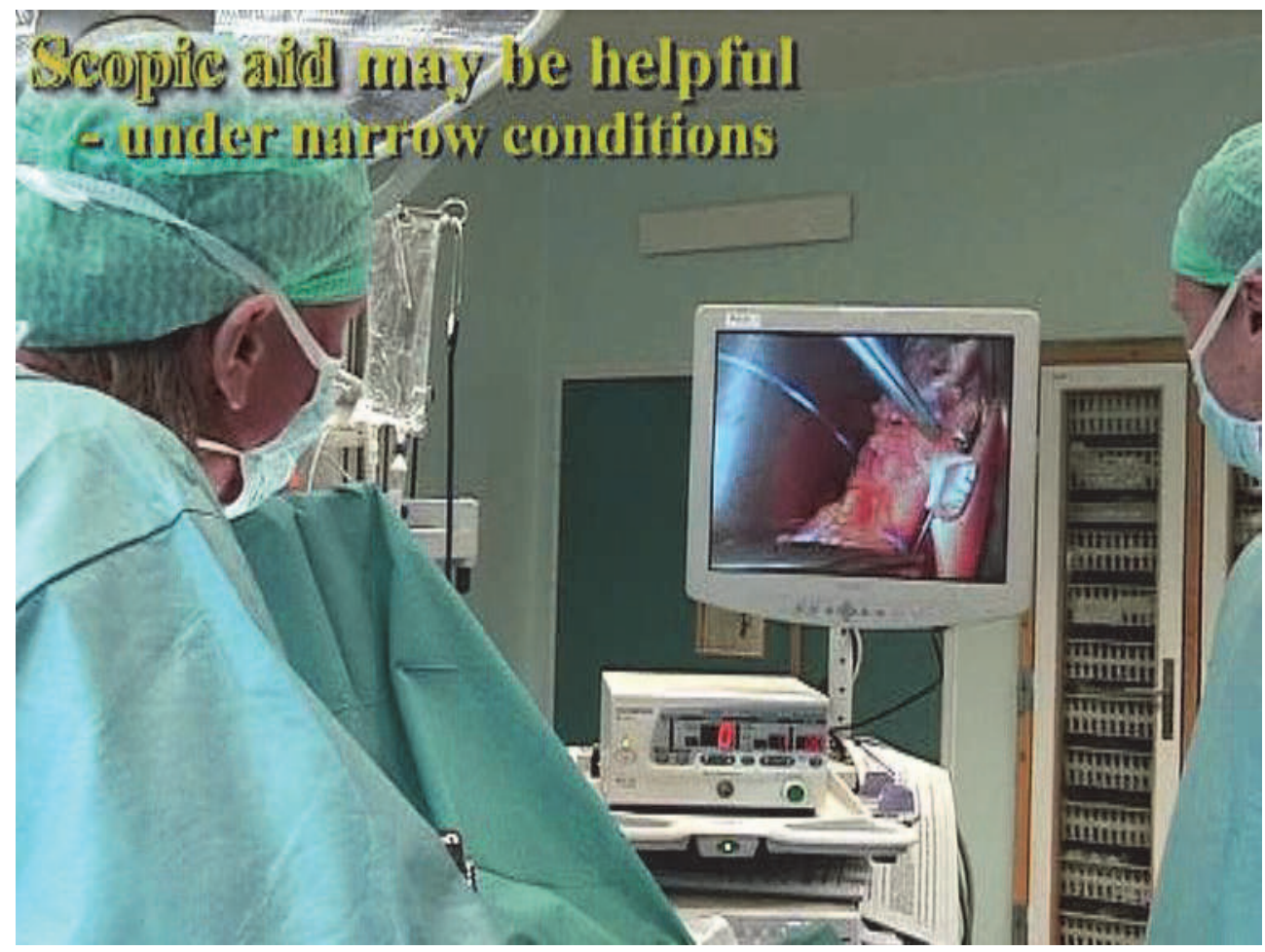

Fig. 4. MIKT scopic aid during the arterial end-to-side anastomosis. 
In most cases the kidney was not moved from the neatly fitting retroperitoneal pouch after revascularization. Reimplantation of the ureter was performed by extravesical technique a.m. Lich-Gregoir, with minimal bladder dissection.

Scopic aid was only found necessary in a few cases under very deep, narrow circumstances. The scope was then simply introduced through the same incision, alongside the instruments, giving a "close up" of the anstomotic area.

A simplistic approach, with minimal dissection/tissue trauma was attempted at all stages.

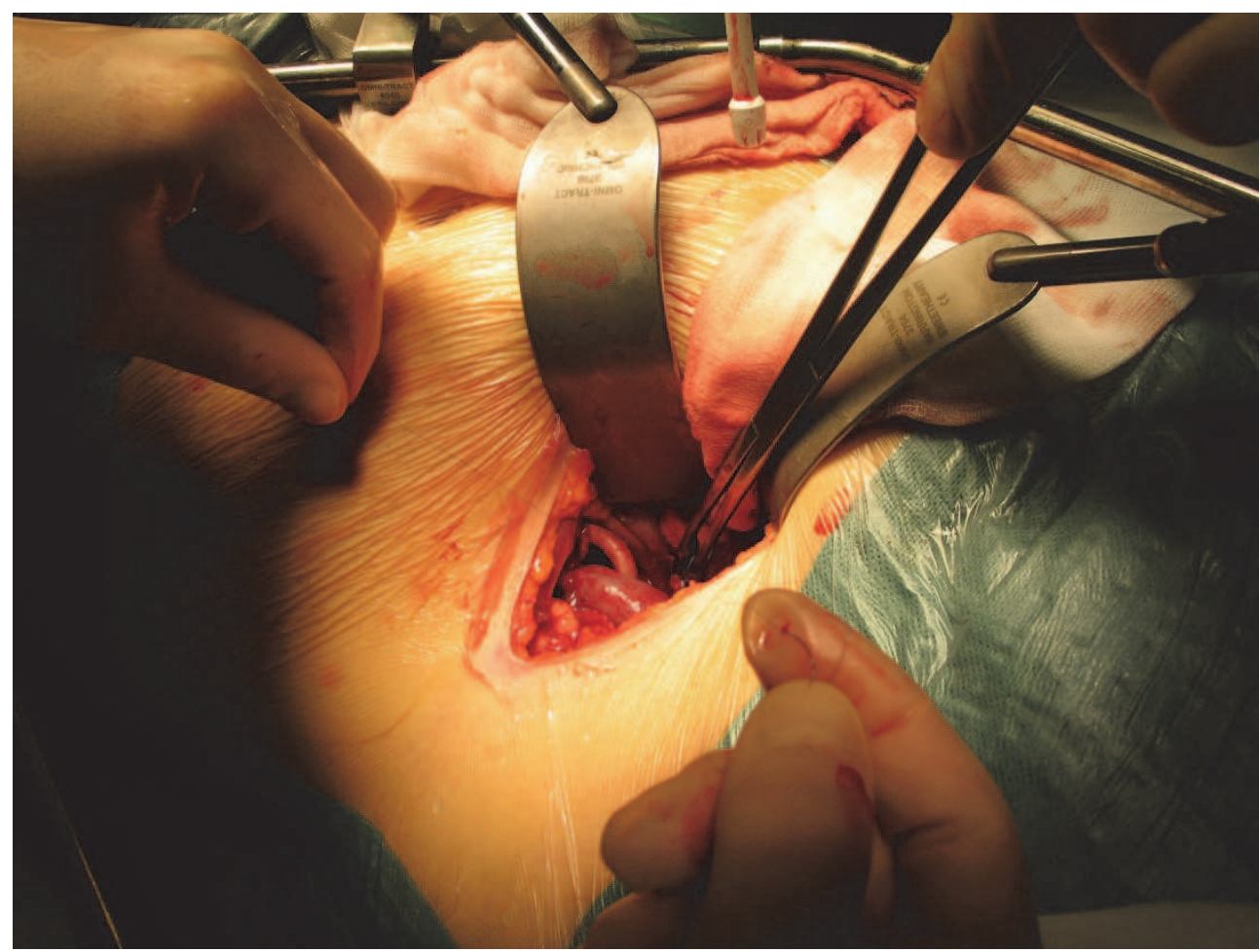

Fig. 5. After revascularisation: The perfused renal artery and vein are seen, while the kidney lies lateral to the skin incision. 


\subsection{MIKT: Results}

A series of patients, transplanted by strict MIKT technique was then compared with matched controls subjected to conventional surgery. From December 2004 to July 2005, 21 kidney recipients were subjected to the new, minimally invasive technique. The MIKT patients constituted a consecutive series of transplantations performed by a single surgeon. A control group, subjected to conventional KTx $(n=21)$ had been concurrently selected to match the MIKT group regarding age, sex, donor source, and primary-/retransplant status. No MIKT procedures were interrupted or converted to COKT. The results have been summarized in Table 1.

\begin{tabular}{|c|c|c|c|}
\hline $\begin{array}{c}\text { RESULTS } \\
\text { [ mean (range)] }\end{array}$ & $\begin{array}{c}\text { MIKT } \\
\mathrm{n}=21\end{array}$ & $\begin{array}{l}\text { Conventional Tx } \\
\qquad \mathbf{n}=\mathbf{2 1}\end{array}$ & $\begin{array}{l}\text { Student } \\
\text { t-test } \\
\text { p-value }\end{array}$ \\
\hline Skin incision length $(\mathrm{cm})$ & $8,1^{*}(7-9)$ & $20,5(17-23)$ & $\mathrm{p}<0,01$ \\
\hline $\begin{array}{l}\text { Operative time } \\
\text { (min) }\end{array}$ & $118^{*}(95-140)$ & $187(130-270)$ & $\mathrm{p}<0,01$ \\
\hline $\begin{array}{l}\text { Analgesic requirementsPostop. } \\
\text { days } 0+1+2 \\
\text { (Morphine Equiv.; mg) }\end{array}$ & $35(3-86)$ & $56(20-173)$ & $\begin{array}{c}\text { n.s. } \\
(p=0,053)\end{array}$ \\
\hline $\begin{array}{c}\text { Hospitalization } \\
\text { (days in hospital postop.) }\end{array}$ & $8,2^{*}(6-13)$ & $12,4(7-29)$ & $p=0,02$ \\
\hline $\begin{array}{c}\text { Delayed graft function } \\
\text { Measured GFR }\end{array}$ & $10 \%(2)$ & $14 \%(3)$ & \\
\hline $\begin{array}{l}\text { 10-12 weeks post-Tx } \\
\text { (Cr-EDTA- Clearance; mean [range]; } \\
\left.\text { ml/min } / 1,73 \mathrm{~m}^{2}\right)\end{array}$ & $57,4(35-81)$ & $51,2(26-72)$ & $\begin{array}{c}\text { n.s. } \\
(p=0,053)\end{array}$ \\
\hline Peroperative incidents & No major & No major & \\
\hline $\begin{array}{c}\text { Surgical } \\
\text { complications/reinterventions } \\
\text { - Lymphocele: Reop. } \\
\text { - Wound dehiscence: Reop. } \\
\text { - Urinary obstruction: Reop. } \\
\text { - Perirenal hemorrhage: Reop. } \\
\text { - Bladder hemorrhage } \\
\text { - Total }\end{array}$ & $\begin{array}{c}2(10 \%) \\
0 \\
0 \\
1(5 \%) \\
0 \\
3(14 \%)\end{array}$ & $\begin{array}{c}3(14 \%) \\
1(5 \%) \\
1(5 \%) \\
1(5 \%) \\
2(10 \%) \\
8(38 \%)\end{array}$ & \\
\hline
\end{tabular}

Table 1. MIKT results. (extracted from Øyen et al., 2006)

Naturally, the MIKT skin incision was very much shorter. There were significant differences in favour of MIKT regarding operative time and postoperative stay in hospital. Furthermore, the analgesic requirements, expressed as morphine equivalents during postoperative days $0+1+2$ were less in the MIKT group, however at non-significant levels. There were less complications and reinterventions in the MIKT recipients, totally $3(14 \%)$ versus $8(38 \%)$ in the open KTx group. Because of the high complication rate in the control group, the total complication/reintervention rate of open KTx outside the study during the inclusion period $(n=97)$ were investigated and found to be $30-40 \%$ (data not shown). 


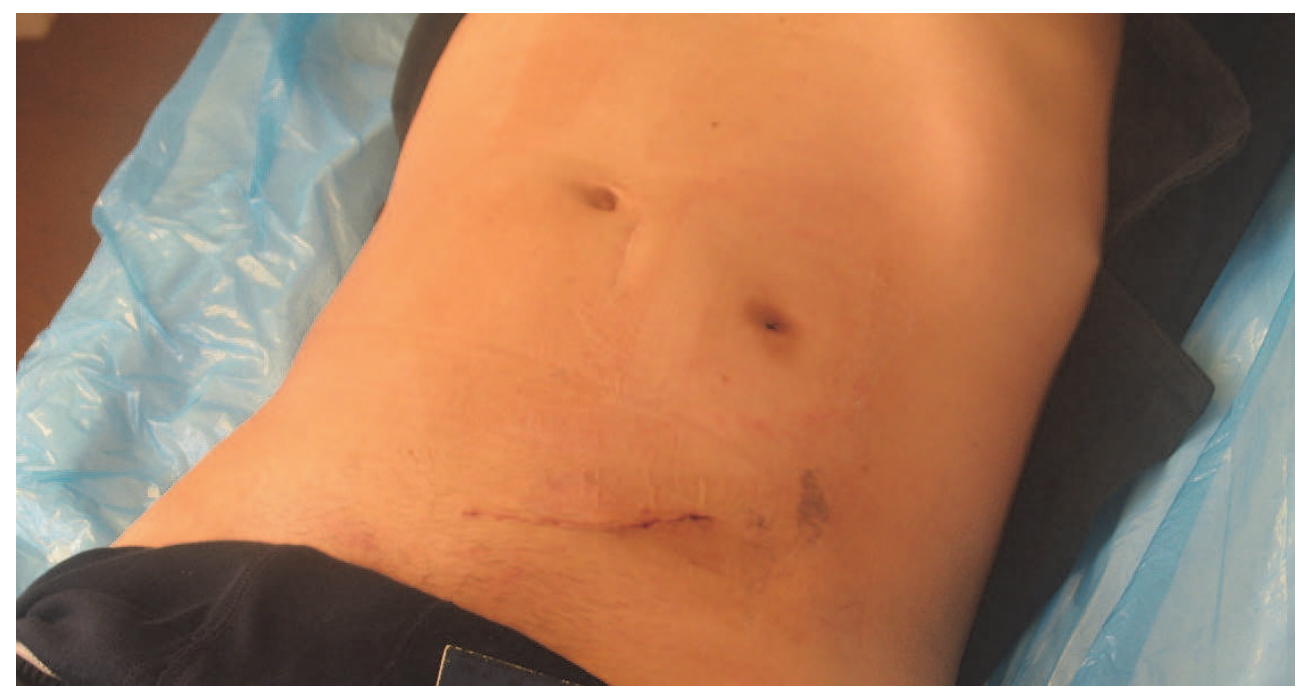

Fig. 6. Exterior result after left-sided MIKT in a slim patient, through a 7,5 cm incision.

\subsection{MIKT: Discussion}

Compared with L-LDN employing a 6-9 $\mathrm{cm}$ skin incision for kidney harvesting, the MIKT incision was only faintly larger $(7-9 \mathrm{~cm})$, and besides the L-LDN was dependent on 2-3 additional laparoscopic ports (5-12 $\mathrm{mm}$ each).

The first MIKT results were good, compared with the open, conventional KTx group and indicated that the procedure might be executed fast (because of its simplicity) and safe. By reducing incision, extent of dissection and thereby tissue trauma, the wound complications would be suspected to be reduced accordingly. Potentially it may also reduce hospitalization, and thereby the risk for nosocomial infections.

A major point about the MIKT approach (also when disregarding the results), was that reduction of tissue trauma appeared particularly appropriate in these patients, with significantly delayed wound healing and a high "background" complication rate. Due to the immunosuppressive theraphy, the incidences of wound dehiscence and incisional hernia were distinctly higher in $\mathrm{Tx}$ recipients, in particular after the introduction of Sirolimus/Everolimus. For simple reasons, a significant reduction of the abdominal wall incision would be anticipated to reduce these wound-related problems. Potentially, the MIKT procedure might also counteract the huge lymphocele/lymph leakage problem, by minimizing the dissection cavity and leaving less space available for fluid expansion.

Except from the single MIKT surgeon's extensive Tx experience, the distinctly shorter MIKT operating time might be explained by the simplified/minimalistic handling of the vessels, the extravesical reimplantation technique, and fast closure of a small incision.

Our data did suggest the same beneficial effects on postoperative pain/analgesia and recovery, that had been documented for a wide range of MIS procedures.

During recent years, Tx surgeons in Oslo have in part adopted the MIKT technique, by significantly reducing the size of the incision, even though not conforming strictly to MIKT. A significant reduction in overall KTx complication rates has been observed during 20082011, which may be partly attributed to reduced incision size and thereby tissue trauma. 


\section{Minimally invasive video-assisted KTx (MIVAKT) - The South Chorean experience (2007)}

In 2007 a minimally invasive, partly video-assisted KTx technique (MIVAKT) was described by a South Chorean group (Seong-Pyo et al., 2007, Park et al., 2008) - obviously quite independent of the previous 'da Vinci robot' and MIKT reports.

\subsection{MIVAKT: Method/Technique}

The MIVAKT pocedure was carried out in 20 patients. Clinical variables were compared with the conventional KTx method. A 7-8 cm skin incision was employed. By means of a scopic balloon instrument a retroperitoneal space was created for the kidney. The vascular anastomoses and ureteroneocystostomy were performed under both direct vision and video-assisted aid.

\subsection{MIVAKT: Results/Conclusion}

The average length of the wound incision was $7-8 \mathrm{~cm}$, placed below the belt line. The average operating time were $186 \mathrm{~min}$. Less analgesics was given compared with conventional methods. There was one postoperative complication, a mild lymphocele. All patients showed normalized serum creatinine levels within 4 days post-Tx and normal findings on postoperative ultrasound and renal scintigraphy.

MIVAKT was shown to be technically feasible and might offer benefits in terms of better cosmetic outcomes, less pain, and quicker recuperation, compared with conventional KTx.

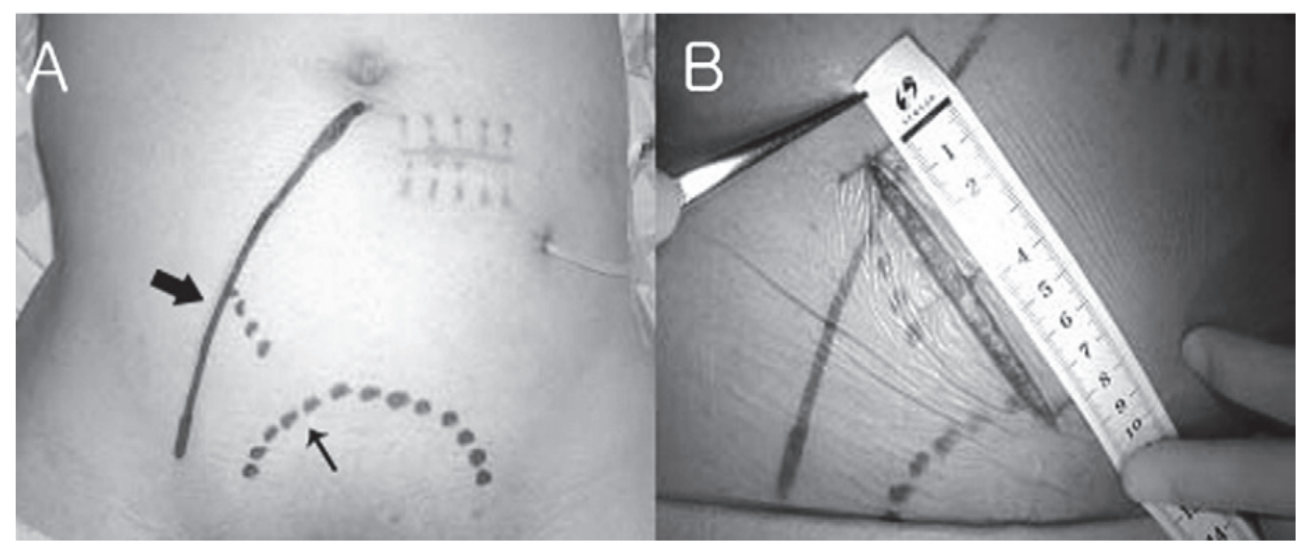

Fig. 7. (A) The location and course of the external iliac vessels (thick arrow) and the contour of the urinary bladder (thin arrow), marked preoperatively using ultrasound. (B) The $7-8 \mathrm{~cm}$ oblique incision. (Seong-Pyo et al., 2007)

\subsection{MIVAKT: Discussion}

We consider the transverse (horizontal) MIKT incision to offer better access to the iliac vessels, than the oblique MIVAKT incision. Furthermore, it is not at all necessary to use a laparoscopic balloon dissector to create the retroperitoneal space. A kidney-fitting retroperitoneal pouch is easily and safely made by hand/retractors through a minimal incision. 
The video-assisted MIVAKT approach is interesting. Though, in the MIVAKT series, it seems like the vascular anastomoses for the most part were carried out under direct vision. In the MIVAKT discussion it is stated that "The grafted kidney was hung over the skin incision during the vascular anastomosis because the procedure is nearly impossible after the placing of the grafted kidney in the retroperitoneal space." This is not at all 'impossible'; but exactly what the MIKT technique is all about. Both the venous and arterial MIKT anastomoses were performed with the kidney in its final retroperitoneal position, suturing the back walls from the inside.

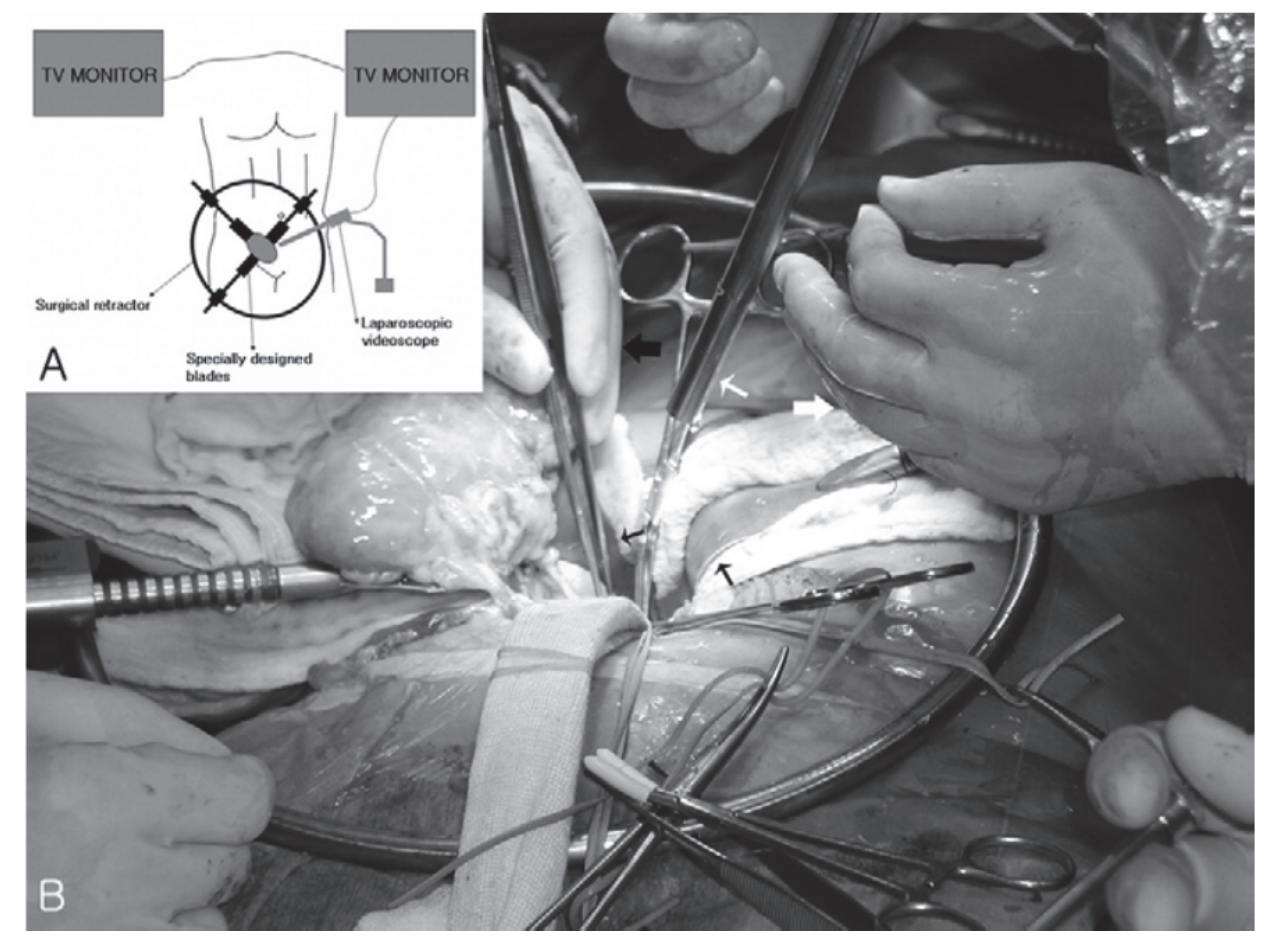

Fig. 8. (A) The circular retraction system and video-assisted TV monitoring. (B) The kidney was placed just above the skin incision during the vascular anastomoses. The laparoscope (thin white arrow) was found useful for visualisation and illumination. (Seong-Pyo et al., 2007)

\section{Laparoscopic KTx - A case report from Barcelona (2010)}

In 2010 a spanish group presented a case report on KTx by means of regular laparoscopic access, using 4 trocars and a Pfannenstiel incision (Rosales et al.).

\subsection{Laparoscopic KTx: Method/Technique}

With the recipient in the left lateral decubitus position, a hand-port was placed into a $7 \mathrm{~cm}$ Pfannenstiel incision. One trocar was put through the hand-port, while three more trocars were introduced in the right hemiabdomen. 


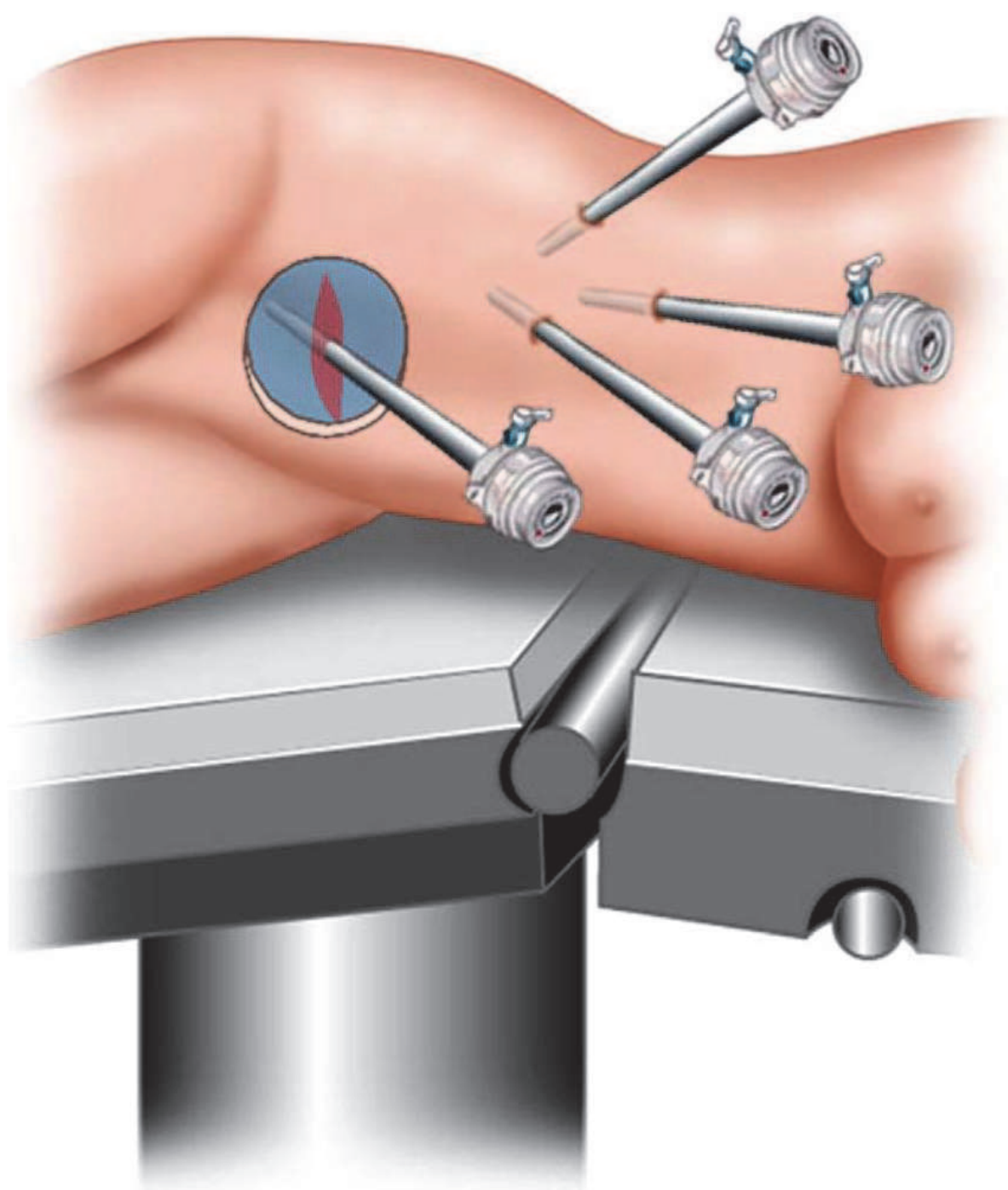

Fig. 9. Trocar positioning. Pfannenstiel incision. (Rosales et al., 2010) 

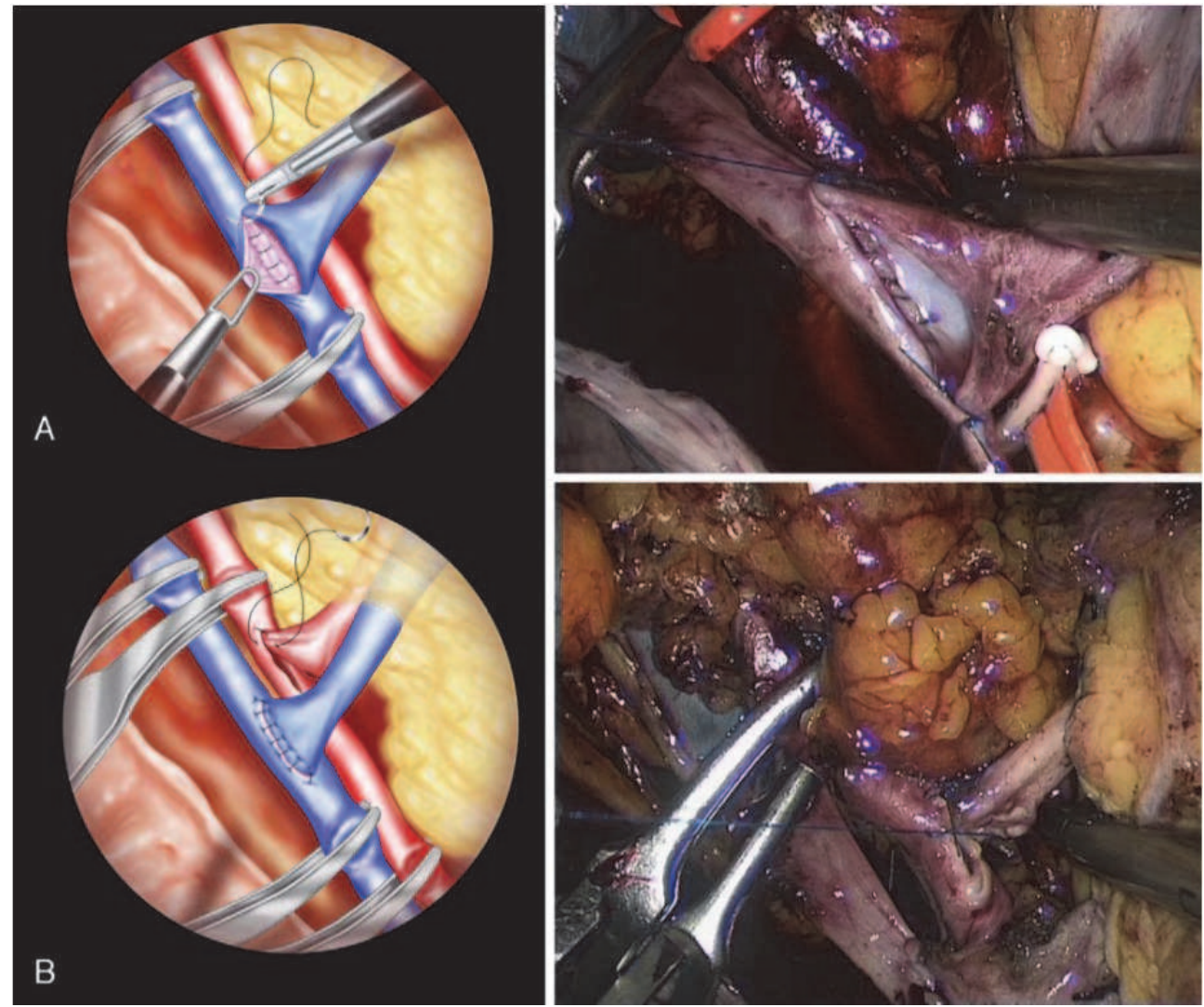

Fig. 10. Laparoscopic venous and arterial end-to-side anastomoses (Rosales et al., 2010). 
By making a retroperitoneal, pelvic window ,the right external iliac vessels were dissected free. The kidney was introduced through the hand-port, and end-to-side anastomoses were performed by bulldog clamping through the hand-port and continous suture.

The ureterovesical anastomose was done by a modified Taguchi technique. Finally, the kidney graft was placed extraperitoneally by continuous suture of the peritoneal window.

\subsection{Laparoscopic KTx: Results}

Surgical time was $240 \mathrm{~min}$, with $300 \mathrm{~cm}^{3}$ bleeding. Cold ischemia time was $182 \mathrm{~min}$. The postoperative course was uneventful and functionally satisfactory. Serum creatinine decreased progressively, to $73 \mu \mathrm{mol} / 1$ on the day of discharge. Stay in hospital was 14 days.

\subsection{Laparoscopic KTx: Discussion}

A laparoscopic KTx operating time of 4 hours seems too much, when MIKT can be executed in 2 hours, and with a total incision size that is probably smaller, when taking into account the 3 additional laparoscopic ports. The transverse (7-9) $\mathrm{cm}$ MIKT incision in the iliac fossa offers excellent direct access to the anastomotic area of the external iliac vessels. And regarding safety towards vacular incidents, the laparoscopic approach must be considered inferior.

Altogether, it seems unnecessary to perform the vascular anastomoses by laparoscopic technique - when these can be performed openly by an incision that is nevertheless needed for decent introduction/transplantation of the kidney.

\section{Minimally invasive renal auto-transplantation (MI-Auto-KTX) (2010)}

By combining "hand- assisted laparoscopic nephrectomy" and MIKT - using the same incision (7-9 cm) for hand-assistance, kidney harvesting, and transplantation - we have during 2009-2011 conducted "Minimally invasive renal auto-transplantation" (MI-AutoKTx) in 6 patients. The first two MI-Auto-KTx cases have allready been documented and published (Øyen et al., 2010).

\subsection{MI-Auto-KTx: Method}

Laparoscopic hand-assisted nephrectomy: The handport incision $(7-8 \mathrm{~cm})$ was made medially in the right iliac fossa; displaced laterally compared with the usual Pfannenstiel LLDN incision.

Extracorporeal 'back bench' preparartion: In the first case (female 38 years; renal artery aneurysm) it was possible to maintain a single arterial stem, after resection of the $16 \mathrm{~mm}$ aneurysm. In the second case (female 55 years; ureter lesion) three renal arteries had to be reconstructed.

MIKT: We utilized the handport incision, targeted on the iliac vessels, without extension. The meticulously prepared kidney was placed in a small/fitting, retroperitoneal pouch; and anastomosed to the iliac vessels. Reimplantation of the ureter was performed by extravesical technique.

\subsection{MI-Auto-KTx: Results}

Total operative times were $335 \mathrm{~min}$ and $434 \mathrm{~min}$, respectively. In both cases the postoperative course was uneventful, and the patients were transferred to the local hospital 


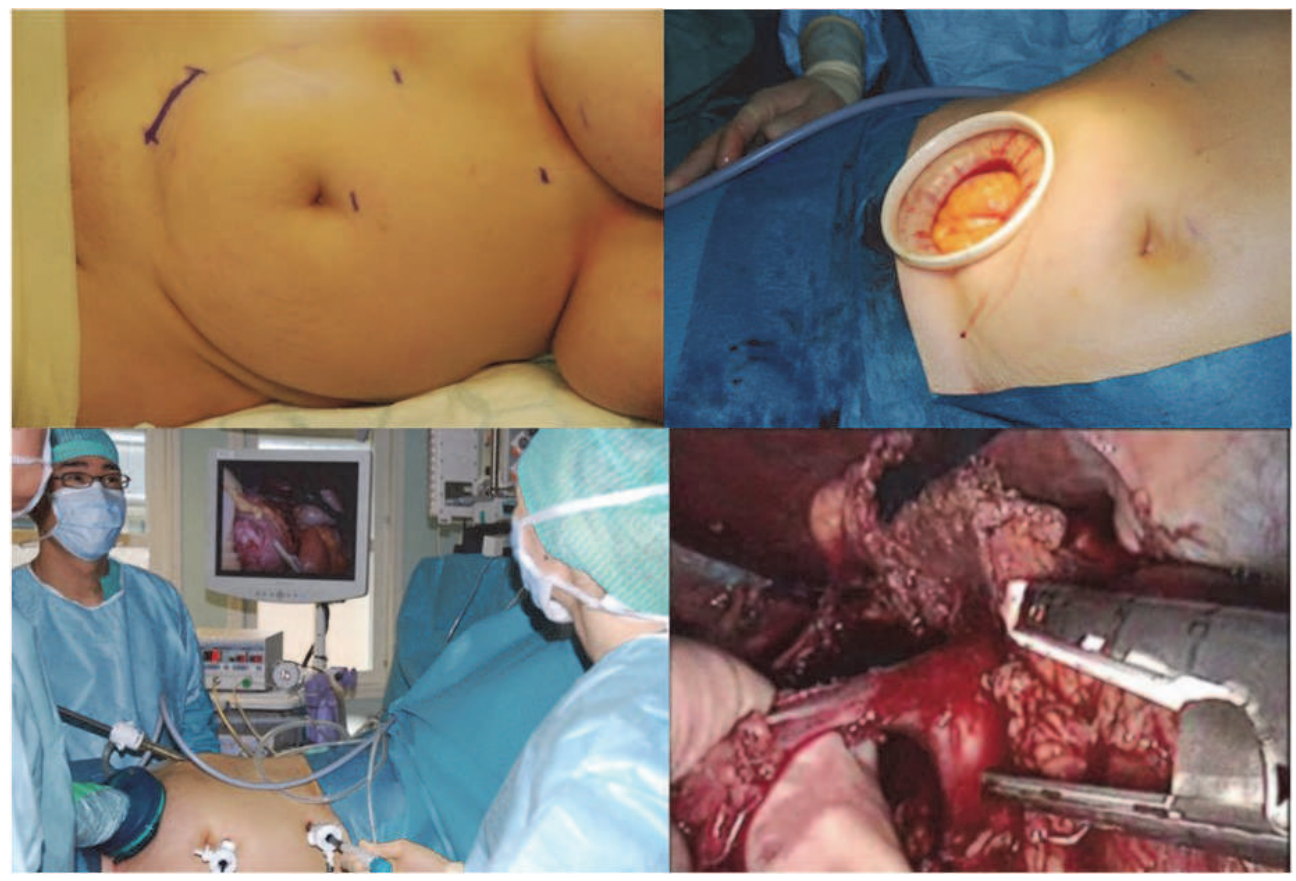

Fig. 11. MI-Auto-KTx: Laparoscopic, right-sided, hand-assisted nephrectomy; by a 7-8 cm medial "transplant incison", using GelPort and 3 trocars. The right renal vein is stapled and divided flush with the caval vein. (Øyen et al., 2010) 
at day 4/day 5 . When examined $3 \mathrm{mts}$ postoperatively, both auto-transplants were shown to have excellent function by renal scintigraphy.

\subsection{MI-Auto-KTx: Discussion}

Our first two MI-Auto-KTx cases have demonstrated that a traditionally major surgical procedure, with extensive incisions/tissue trauma, can be made minimally invasive, by a similar incision as that used for L-LDN. Taking into regard the highly traumatic conventional incisions, we expect the generally proven minimally invasive benefits to be considerable.

\section{Considerations about the future}

The minimally invasive KTx procedures have so far not gained widespread acceptance and still seem to be at a "pioneer stage". However, considering the rapid evolution of MIS during the last two decades, there is little reason to believe that KTx and Auto-KTx in future will be excluded from this development.

Since $a \geq 6 \mathrm{~cm}$ incision will anyway be needed for decent introduction of the kidney (except for the possibilty of introduction through natural orifices), we think the MIKT procedure is the most suited for further developments in this field.

\section{References}

Dubois F, Icard P, Berthelot G \& Levard H (1991). Coelioscopic cholecystectomy: preliminary report of 36 cases. Ann Surg, 211: 60-2.

Harrell AG, \& Beniford BT. (2005). Minimally invasive abdominal surgery: lux et veritas past, present, and future. Am J Surg, Vol 190, No 2, pp 239-43.

Hoznek A, Zaki SK, Samadi DB, Salomon L, Lobontiu A, Lang P \& Abbou CC (2002). Robotic assisted kidney transplantation: an initial experience.. J Urol, Vol 167, pp 1604-06.

Hoznek A, Hubert,J, Antiphon, Gettman MT, Hemal AK \& Abbou CC (2004). Robotic renal surgery. Urol Clin N Am, Vol 31, pp 731-76.

Khanna A \& Horgan S (2011). A laboratory training and evaluation technique for robot assisted ex vivo kidney transplantation. Int J Med Robot. Vol 7, No 1, pp 118-122.

McCullough CS, Soper NJ, Clayman RV, So SSK, Lendrisak MD, \& Hanto DW (1991). Laparoscopic drainage of a post-transplant lymphocele. Transplantation, Vol 51, No 3, pp 725-27.

Øyen O, Scholz T, Hartmann A \& Pfeffer P (2006). Minimally invasive kidney transplantation: The first experience.. Transpl Proc , Vol 38, pp 2798-2802.

Øyen O, Scholz T, Hartmann A \& Pfeffer P (2006). Minimal invasive kidney transplantation - The first experience. Transplantation, Vol 82, Suppl 2, pp 930-31.

Øyen O, Lien B, Line P-D, \& Pfeffer P (2010). Minimally invasive renal auto-transplantation: The first report (2010). J Surg Res, Vol 164, pp e181-84.

Park SC, Kim SD, Kim JI, \& Moon IS (2008). Minimal skin incision in living kidney transplantation. Transpl Proc, Vol 40, pp 2347-48. 
Ratner LE, Ciseck LJ, \& Moore RG.(1995) Laparoscopic live donor nephrectomy. Transplantation;, Vol 60, No 9, pp 1047-49.

Rosales A, Salvador JT, Urdaneta G, Patino D, Montllo M, Esquena S, Caffaratti J, Ponce de Leon J, Guirado L \& Villavicencio H (2010). Laparoscopic kidney transplantation. Eur Urol, Vol 5 7, pp 164-67.

Seong-Pyo M, Jeong-Whan C, Kuyong-Jong K, Gui-Ae J, Min-Woo C, Young-Joon A \& Seong-Whan K (2007). Minimally invasive video-assisted kidney transplantation (MIVAKT) (2007). J Surg Res Vol 141, pp 204-10.

Wolf JSJ, Tchetgen MB \& Merion RM (1998). Hand-assisted laparoscopic live donor nephrectomy. Urology, Vol 52, No 5, pp 885-87. 


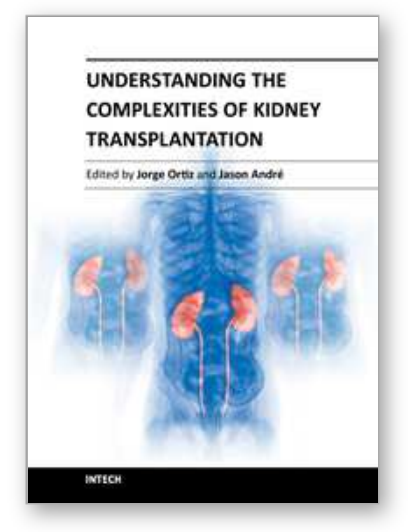

\author{
Understanding the Complexities of Kidney Transplantation \\ Edited by Prof. Jorge Ortiz
}

ISBN 978-953-307-819-9

Hard cover, 564 pages

Publisher InTech

Published online 06, September, 2011

Published in print edition September, 2011

Kidney transplantation is a complex field that incorporates several different specialties to manage the transplant patient. This book was created because of the importance of kidney transplantation. This volume focuses on the complexities of the transplant patient. In particular, there is a focus on the comorbidities and special considerations for a transplant patient and how they affect kidney transplant outcomes. Contributors to this book are from all over the world and are experts in their individual fields. They were all individually approached to add a chapter to this book and with their efforts this book was formed. Understanding the Complexities of Kidney Transplantation gives the reader an excellent foundation to build upon to truly understand kidney transplantation.

\title{
How to reference
}

In order to correctly reference this scholarly work, feel free to copy and paste the following:

Ole Øyen (2011). Minimally Invasive Renal Transplantation, Understanding the Complexities of Kidney Transplantation, Prof. Jorge Ortiz (Ed.), ISBN: 978-953-307-819-9, InTech, Available from: http://www.intechopen.com/books/understanding-the-complexities-of-kidney-transplantation/minimallyinvasive-renal-transplantation

\section{INTECH}

open science | open minds

\section{InTech Europe}

University Campus STeP Ri

Slavka Krautzeka 83/A

51000 Rijeka, Croatia

Phone: +385 (51) 770447

Fax: +385 (51) 686166

www.intechopen.com

\section{InTech China}

Unit 405, Office Block, Hotel Equatorial Shanghai

No.65, Yan An Road (West), Shanghai, 200040, China

中国上海市延安西路65号上海国际贵都大饭店办公楼 405 单元

Phone: $+86-21-62489820$

Fax: $+86-21-62489821$ 
(C) 2011 The Author(s). Licensee IntechOpen. This chapter is distributed under the terms of the Creative Commons Attribution-NonCommercialShareAlike-3.0 License, which permits use, distribution and reproduction for non-commercial purposes, provided the original is properly cited and derivative works building on this content are distributed under the same license. 